\title{
Obtaining humic materials by mechanochemical reduction
}

\author{
Natalya Yudina ${ }^{1-}$, Elizaveta Linkevich ${ }^{1}$, Anna Saveleva $^{1}$, and Oleg Lomovsky ${ }^{2}$ \\ ${ }^{1}$ Institute of Petroleum Chemistry, Siberian Branch, Russian Academy of Sciences, Akademicheskii \\ Ave., 4, Tomsk, 634055, Russia \\ ${ }^{2}$ Institute of Solid State Chemistry and Mechanochemistry, Siberian Branch, Russian Academy of \\ Sciences, Kutateladze Str., 18, Novosibirsk, 630128, Russia
}

\begin{abstract}
In the study, a mechanochemical modification of peat was carried out, leading to an increase in the number of functional groups and an increase in the solubility of humic complexes with metals. It was shown that the mechanical activation of peat in the presence of $\mathrm{Zn}$ significantly increased the yield of extractable fulvic acids. An analysis of the spectral coefficients showed that humic and fulvic acids extracted from peat were characterized by an increased content of alcohol hydroxyl groups, $\mathrm{C}-\mathrm{O}$ carbohydrate moieties, and carboxyl groups.
\end{abstract}

\section{Introduction}

Humic (HAs) and fulvic acids (FAs) are the key organic components of solid caustobioliths and soils. The content and composition of these acids vary within a broad range and largely depend not only on their origin but also on a particular technique used for their extraction. Caustobioliths are complex multi-component polydisperse semi-colloidal high-molecularweight systems. Bitumens, poorly and easily hydrolyzable substances, and humic components found in caustobioliths form micro- and macroaggregates, which ensure composition consistency of organic substances and prevent their decomposition $[1,2]$.

Humic substances are irregular copolymers of aromatic oxypolycarboxylic acids in which the aromatic carbon backbone is substituted for carbohydrate, nitrogen-containing, and alkyl moieties and functional groups. Owing to this structure, the humic molecular macroaggregate can be modified, so that its solubility is enhanced and fundamental properties are altered.

Chemical modification of the structure of HAs, which aims to increase the number of functional groups and enhance the solubility of humic complexes with metals, involves sulfonation [8] and oxidative destruction [3-5]. Aromatic compounds with varying numbers of substituents $(-\mathrm{COOH},-\mathrm{OH},-\mathrm{OMe},-\mathrm{CHO}$ groups, etc.), as well as aliphatic acids, dicarboxylic acids, and alcohols, are the products of oxidative destruction of HAs.Oxidative destruction under hard conditions gives rise to low-molecular-weight compounds; the initial macromolecular structure of humic substances is not retained. Soft oxidation with ozone

— Corresponding author: natal@ipc.tsc.ru 
makes it possible to increase the number of oxygen-containing groups in humic substances without rupturing the carbon backbone structure [6].

Targeted modification of the structure of humic substances can be performed through mechanochemical activation of solid caustobioliths [7-12]. Deformation of humincontaining substances may alter the interatomic and intermolecular bonds: these bonds are weakened, and mechanical rupture of chemical bonds accompanied by formation of reactive free radicals can take place in the extreme case [13, 14]. Solid-phase mechanochemical reactions between humic substances and alkali metals yield watersoluble humates. Humic preparations are enriched with biogenic elements during solidphase reactions between HAs and mineral salts.

The objective of this study was to identify the structural changes and physicochemical properties of humic acids isolated from peat after mechanical activation under reducing conditions.

\section{Study object and Methods}

High-moor peat (decomposition degree, $5 \%$; ash value, $4.9 \%$ ) was used as a study object.

The peat was subjected to mechanical activation in a AGO-2 planetary mill in the presence of $0.5 \%$ ultrafine-grained powder $\mathrm{Zn}$ powder at the drum rotation speed of 1820 $\mathrm{rpm}$ and the centrifugal acceleration of $600 \mathrm{~m} / \mathrm{s}^{2}$. Steel balls $8-10 \mathrm{~mm}$ in diameter were used as the grinding bodies. The weight of the balls loaded into the drum was $0.2-0.5 \mathrm{~kg}$; sample weight was 15-20 g; and treatment duration was 2 min.

Humic acids (HAs) were extracted from coal by treating it with $0.1 \mathrm{M} \mathrm{NaOH}(150 \mathrm{ml}$ of the solution per $\mathrm{g}$ of the sample) at $90^{\circ} \mathrm{C}$ for $1 \mathrm{~h}$. The alkaline extraction was repeated three times. Humic acids in the alkaline solution were precipitated with $4 \% \mathrm{HCl}$ until pH 2 was reached. The reddish brown amorphous precipitate of HAs was isolated by centrifugation, washed with distilled water until $\mathrm{pH} 7$ was reached, and dried to constant weight in a Petri dish in a vacuum oven.

After the precipitation of HAs, fulvic acids (FAs) were isolated from the acid solution by sorption on a column packed with Amberlite XAD-8 resin. The sorbed FAs were eluted with $0.1 \mathrm{M} \mathrm{NaOH}$ solution. The resulting alkaline solution of FAs was desalinated on a KU-2-8 cation exchanger that had been preliminarily converted to the $\mathrm{H}$-form by passing 30 volumes of $1 \mathrm{M} \mathrm{HCl}$ through it.

The moiety composition of HAs was determined by ${ }^{13} \mathrm{C}$ NMR spectrometry on a Bruker 300 radio-spectrometer (Germany) at an operating frequency of $100 \mathrm{MHz}$ using the fast Fourier transform accumulation method. The spectral scan width was $\sim 26,000 \mathrm{~Hz}$; the time of recording free induction decay (FID) signal was $0.6 \mathrm{~s}$; the interpulse interval (Td) was 8 $\mathrm{s}$ at a pulse width of $90^{\circ}$; and the time of spectrum accumulation was $24 \mathrm{~h}$. A weighed portion of the sample (50-70 mg) was dissolved in $0.7 \mathrm{~cm}^{3}$ of $0.3 \mathrm{M} \mathrm{NaOD}$.

The IR spectra of HA were recorded using $\mathrm{KBr}$ pellets (at a 1: 300 sample : KBr ratio) on a Nicolet-5700 IR spectrometer.

\section{Results and Discussion}

Figure 1 shows that mechanical activation of peat in the presence of $\mathrm{Zn}$ significantly increased the yield of extractable FAs. 


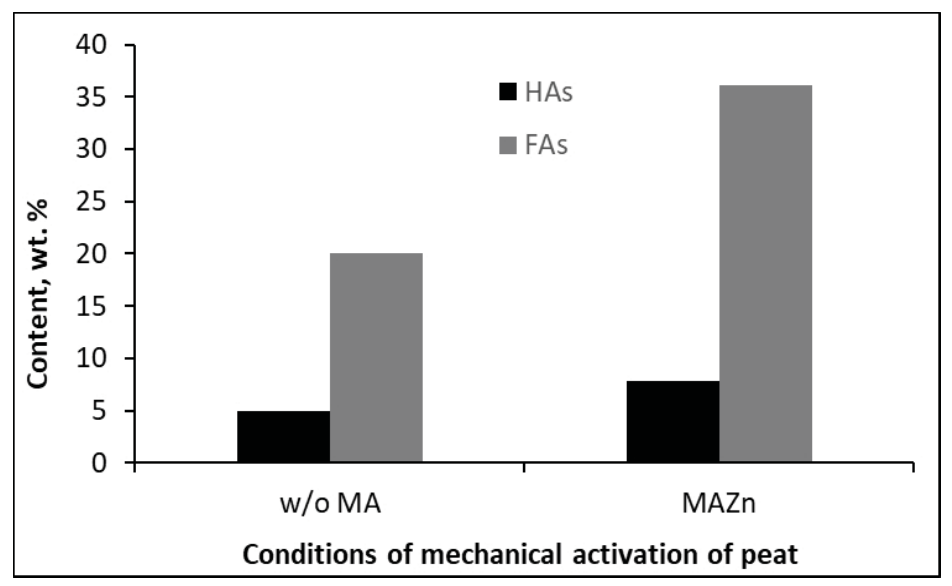

Fig. 1. The yields of HAs and FAs from untreated peat (w/o MA) and peat subjected to mechanical activation in the presence of $\mathrm{Zn}(\mathrm{MAZn})$.

Mechanical activation of peat in the presence of $\mathrm{Zn}$ was found to cause significant changes in the structure of HAs and FAs. An analysis of the moiety composition (Table 1) showed that the contents of carbonyl and quinoid moieties within HA macromolecules in the peat subjected to mechanical activation in the presence of $\mathrm{Zn}$ were substantially reduced. Meanwhile, the contents of carbohydrate moieties $\left(\mathrm{C}_{\mathrm{alk}} \mathrm{O}\right)$ and substituted aromatic carbon atoms $\left(\mathrm{C}_{\mathrm{ar}} \mathrm{C}, \mathrm{H}\right)$ increased significantly, and the content of oxidized aromatic structures $\left(\mathrm{C}_{\mathrm{ar}} \mathrm{O}\right)$ decreased twofold. In turn, this reduced the ratio between the hydrophilic and hydrophobic components (HPL/HPB).

Table 1. The content of carbon atoms in the structural fragments of HAs and FAs (according to the ${ }^{13} \mathrm{C}$ NMR data).

\begin{tabular}{|c|c|c|c|c|c|c|c|}
\hline \multirow[b]{2}{*}{$\begin{array}{l}\text { Conditions of } \\
\text { mechanical } \\
\text { activation }\end{array}$} & \multicolumn{7}{|c|}{ Content of carbon atoms in structural fragments, rel. \% } \\
\hline & $\begin{array}{c}\mathrm{COO}^{-}, \\
\mathrm{CO}^{-} \\
\mathrm{C}_{\text {quin }}\end{array}$ & $\mathrm{C}_{\mathrm{ar}} \mathrm{O}$ & $\mathrm{C}_{\mathrm{ar}} \mathrm{C}, \mathrm{H}$ & $\mathrm{C}_{\text {alk }} \mathrm{O}$ & $\mathrm{CH}_{3} \mathrm{O}$ & $\mathrm{C}_{\text {alk }}$ & HPL/HPB \\
\hline \multicolumn{8}{|c|}{ HAs } \\
\hline w/o MA & 17.7 & 13.2 & 15.9 & 24.5 & 4.2 & 24.5 & 1.47 \\
\hline MA & 15.9 & 14.5 & 16.5 & 23.9 & 4.0 & 25.0 & 1.40 \\
\hline MAZn & 8.7 & 5.6 & 21.0 & 32.2 & 3.9 & 28.2 & 1.03 \\
\hline \multicolumn{8}{|c|}{ FAs } \\
\hline w/o MA & 14.0 & 14.9 & 12.0 & 34.1 & 2.0 & 19.9 & 2.34 \\
\hline MAZn & 15.0 & 16.3 & 13.3 & 28.5 & 3.6 & 20.6 & 1.94 \\
\hline
\end{tabular}

As compared to HAs, the moiety composition of FAs was characterized by an increased content of carbon in the carbohydrate and oxidized aromatic structures, while the contents of substituted aromatic and alkyl carbon atoms were reduced. Mechanical activation of peat in the presence of $\mathrm{Zn}$ increased the contents of alkyl and oxidized aromatic moieties in extractable FAs.

IR spectroscopy results were used to calculate the spectral coefficients for HAs and FAs (Table 2), which are the optical densities of absorption bands normalized with respect to $\mathrm{D}_{1610}$ of the band corresponding to aromatic polyconjugated systems $\left(1610 \mathrm{~cm}^{-1}\right)$. An analysis of the spectral coefficients demonstrated that HAs and FAs extracted from peat subjected to mechanical activation in the presence of $\mathrm{Zn}$ were characterized by elevated contents of alcohol hydroxyl groups $\left(\mathrm{D}_{1170} / \mathrm{D}_{1610}\right), \mathrm{C}-\mathrm{O}$ carbohydrate moieties $\left(\mathrm{D}_{1070} / \mathrm{D}_{1610}\right)$, and carboxyl groups $\left(\mathrm{D}_{1720} / \mathrm{D}_{1610}\right)$. 
Table 2. The functional composition of HAs and FAs according to the IR spectroscopy data.

\begin{tabular}{|c|c|c|c|c|c|c|}
\hline $\begin{array}{c}\text { Conditions of } \\
\text { MA }\end{array}$ & $\begin{array}{c}\mathbf{D}_{\mathbf{1 0 7 0}} / \\
\mathbf{D}_{\mathbf{1 6 1 0}}\end{array}$ & $\begin{array}{c}\mathbf{D}_{\mathbf{1 1 7 0}} / \\
\mathbf{D}_{\mathbf{1 6 1 0}}\end{array}$ & $\begin{array}{c}\mathbf{D}_{\mathbf{1 2 3 0}} / \\
\mathbf{D}_{\mathbf{1 6 1 0}}\end{array}$ & $\begin{array}{c}\mathbf{D}_{\mathbf{1 7 2 0}} / \\
\mathbf{D}_{\mathbf{1 6 1 0}}\end{array}$ & $\begin{array}{c}\mathbf{D}_{\mathbf{2 8 5 0}} / \\
\mathbf{D}_{\mathbf{1 6 1 0}}\end{array}$ & $\begin{array}{c}\mathbf{D}_{\mathbf{2 9 2 0}} / \\
\mathbf{D}_{\mathbf{1 6 1 0}}\end{array}$ \\
\hline \multicolumn{7}{|c|}{ HAs } \\
\hline W/o MA & 0.63 & 0.70 & 0.75 & 0.93 & 0.78 & 0.88 \\
\hline MA & 0.69 & 0.70 & 0.77 & 0.94 & 0.78 & 0.89 \\
\hline MAZn & 0.76 & 0.91 & 0.83 & 1.01 & 0.99 & 0.97 \\
\hline \multicolumn{7}{|l|}{ FAs } \\
\hline MAZn & 0.97 & 0.87 & 0.86 & 1.37 & 0.83 & 0.93 \\
\hline
\end{tabular}

The yield of FAs and the content of alkyl and oxidized aromatic fragments in the structure of FAs have been increased due to the mechanical activation of peat in the presence of $\mathrm{Zn}$.

The research was funded within the state assignment to ISSCM SB RAS (project No. FWUS-20210005). The work was performed in the framework of the state assignment of the IPC SB RAS (project No. 12103150000498).

\section{References}

1. H. Bossuyt, J. Six, P.F. Hendrix, Soil Biol. Biochem. 37, 251 (2005)

2. R. Lal, Science, 304, 1623 (2004)

3. M.V. Yudov, D.M. Zhilin, A.P. Pankova, et. al. Synthesis, metal-binding properties and detoxifying ability of sulphonated humic acids. In: I.V. Perminova, K. Hatfield, N. Hertkorn, eds. Use of humic substances to remediate polluted environments: from theory to practice, (Dordrecht, The Netherlands: NATO Science Series: IV: Earth and Environmental Sciences, 52, Springer, 2005), pp. 485-498.

4. D.S. Rhee, Y.R. Jung, J. Analyt. Sci. Technol. 13, 241 (2000)

5. G.S. Wang, S.T. Hsieh, C.S. Hong, Wat. Res. 34, 3882 (2000)

6. V.I. Bogdan, Ya.E. Sergeeva, V.V. Lunin, et. al., Appl. Biochem. Microbiol. 54, 198 (2018)

7. A. Muscolo, M. Sidari, E. Attinà, O. Francioso, V. Tugnoli, Soil Sci. Soc. Am. J. 71, 75 (2007)

8. O.I. Lomovsky, V.V. Boldyrev, Mechanochemistry for solving environmental problems: an analytical review. (Novosibirsk: GPNTB (Public Library of Science) SB RAS, 2006.)

9. Å.V. Maltseva, L.V. Nechaev, N.V. Yudina, Solid Fuel Chem. 51, 1 (2017)

10. N.V. Saveleva, Å.V. Maltseva, N.V. Yudina, Solid Fuel Chem. 51, 51 (2017)

11. A.A. Ivanov, Å.V. Maltseva, N.V. Yudina, Solid Fuel Chem. 50, 7 (2016)

12. N.V. Saveleva, N.V. Yudina, Å.M. Berezina, Å.V. Petrova, Solid Fuel Chem. 50, 76 (2016)

13. N.V. Saveleva, A.A. Ivanov, N.V. Yudina, Î.I. Lomovskii, Solid Fuel Chem. 49, 201 (2015)

14. J. Kokorevics, A. Gravitis, Clycoconj. J. 14, 669 (1997) 